\title{
COMPUTERISED PERIMETRY WITH MOVING AND STEADY FIXATION IN CHILDREN
}

\author{
ERKAN MUTLUKAN and BERTIL E. DAMATO \\ Glasgow and Liverpool
}

\section{SUMMARY}

The computer assisted moving eye campimeter (CAMEC) maintains the patient's interest and fixation by using a moving fixation target which must be tracked by the patient using a joystick for the test to proceed. In this study, 32 children were examined with the blind spot test programs of both CAMEC and the Dicon Auto-Perimeter. Among those who completed both tests the blind spot was detected in 18 eyes $(\mathbf{7 5 \%})$ by the Dicon AutoPerimeter and in 24 eyes $(\mathbf{1 0 0 \%})$ by CAMEC. The mean CAMEC score $(61.0 \%)$ was significantly higher than the mean Dicon Auto-Perimeter score (26.6\%). CAMEC allowed better detection and quantification of scotomas in patients more than 4 years of age.

Visual field examination is often omitted in young children with ocular and neurological disease. This is because conventional methods fail when young patients lose interest in the examination or are unable to keep their eye still throughout the procedure. Despite this shortcoming of most tests developed, children use adaptations of conventional oculo-static perimetry. ${ }^{1-4}$

Computer assisted moving eye campimetry (CAMEC) was originally developed primarily for children ${ }^{5}$ and is designed to mimic a computer game to maintain the patient's interest and attention. In addition, the test is designed to prevent loss of fixation by means of a constantly moving fixation target which must be held within a circle by the patient using a joystick. If the patient looks away from the fixation target the spot will escape from the circle and no further stimuli are presented until co-operation is regained. As the capability of different children to perform visual tests varies widely, the speed of the fixation target and hence the difficulty of the tracking procedure is adjusted automatically according to the patient's competence.

The aim of this study was to evaluate the ability of CAMEC to detect the physiological blind spot and to demonstrate visual field defects in children.

Correspondence to: Erkan Mutlukan MD, Henry Ford Hospital, Neuro-ophthalmology Unit, 2799 West Grand Boulevard, Detroit, MI 48202, USA.

\section{MATERIALS AND METHODS}

The CAMEC program uses an IBM-compatible desk top computer equipped with a voice card and a speaker, a 14inch VGA video display monitor, a joystick and a head rest. ${ }^{6}$ The patient must move a circle on the screen using the joystick so that it constantly encloses a randomly moving spot; this task forces the patient to look at the spot and the circle so that the direction of gaze is controlled by the computer. The necessary guidance, training and encouragement are automatically given to each patient by the CAMEC by means of computer 'speech' before and during the actual test.

The level of difficulty of the task of tracking the moving fixation target is automatically adjusted by the computer according to the patient's ability. This is done by varying the speed of the fixation target until it is maintained within the circle for a predetermined time. If the spot is allowed to escape from the circle, the machine emits a continuous beep, and the patient hears the command 'Please move the circle over the spot'. If the spot is successfully kept within the circle then a black test stimulus is presented silently at a seemingly random location on the white screen. Awareness of this stimulus is signalled by the patient pressing a button on the joystick so that a rewarding bleep is achieved. If the button is pressed before the stimulus appears, the stimulus is delayed and the computer says 'Do not guess!'

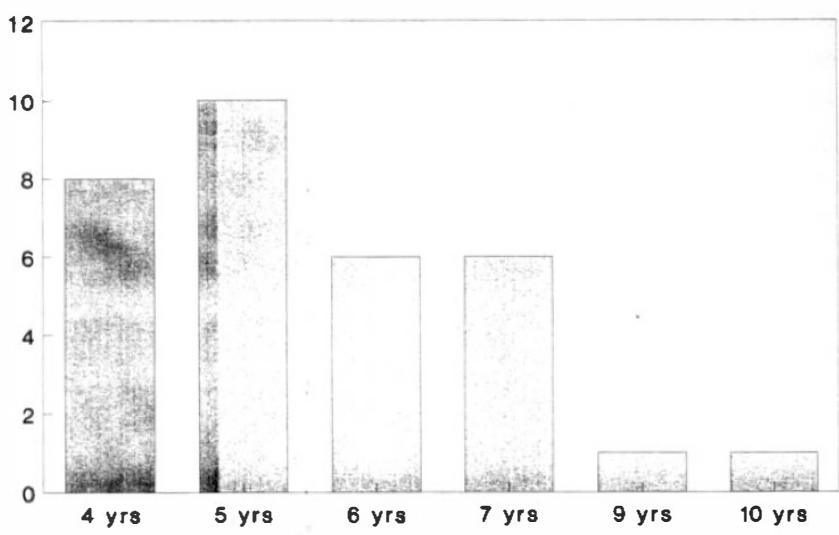

Fig. 1. The age distribution of the patients tested $(n=32)$. 


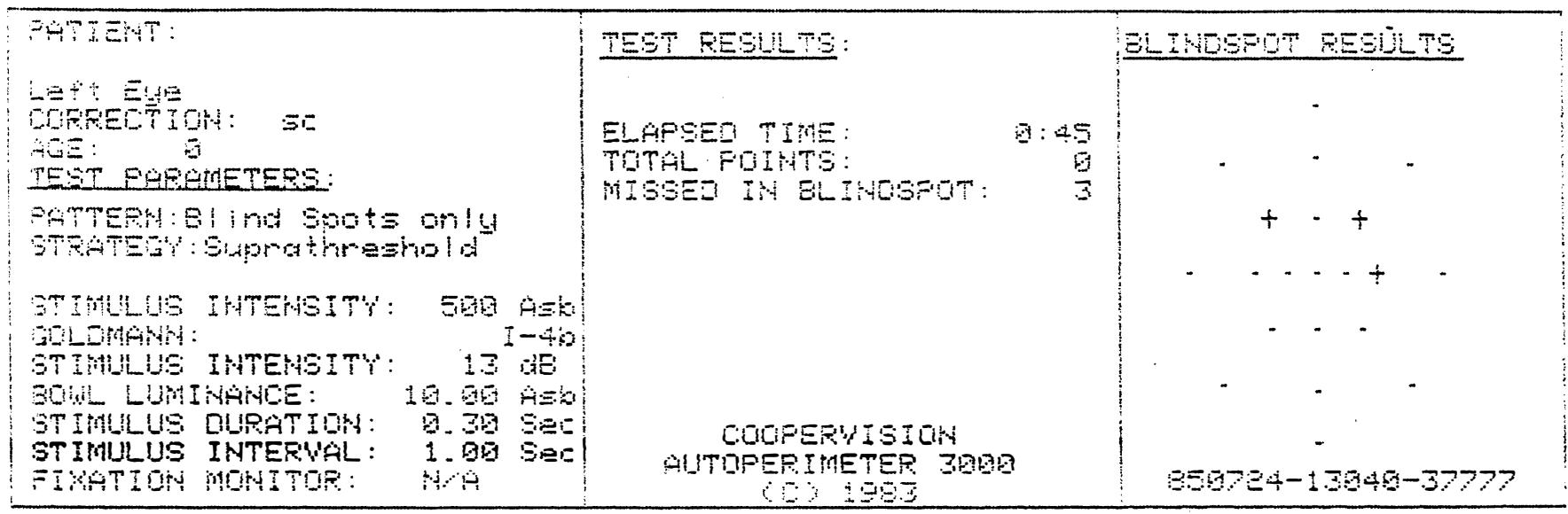

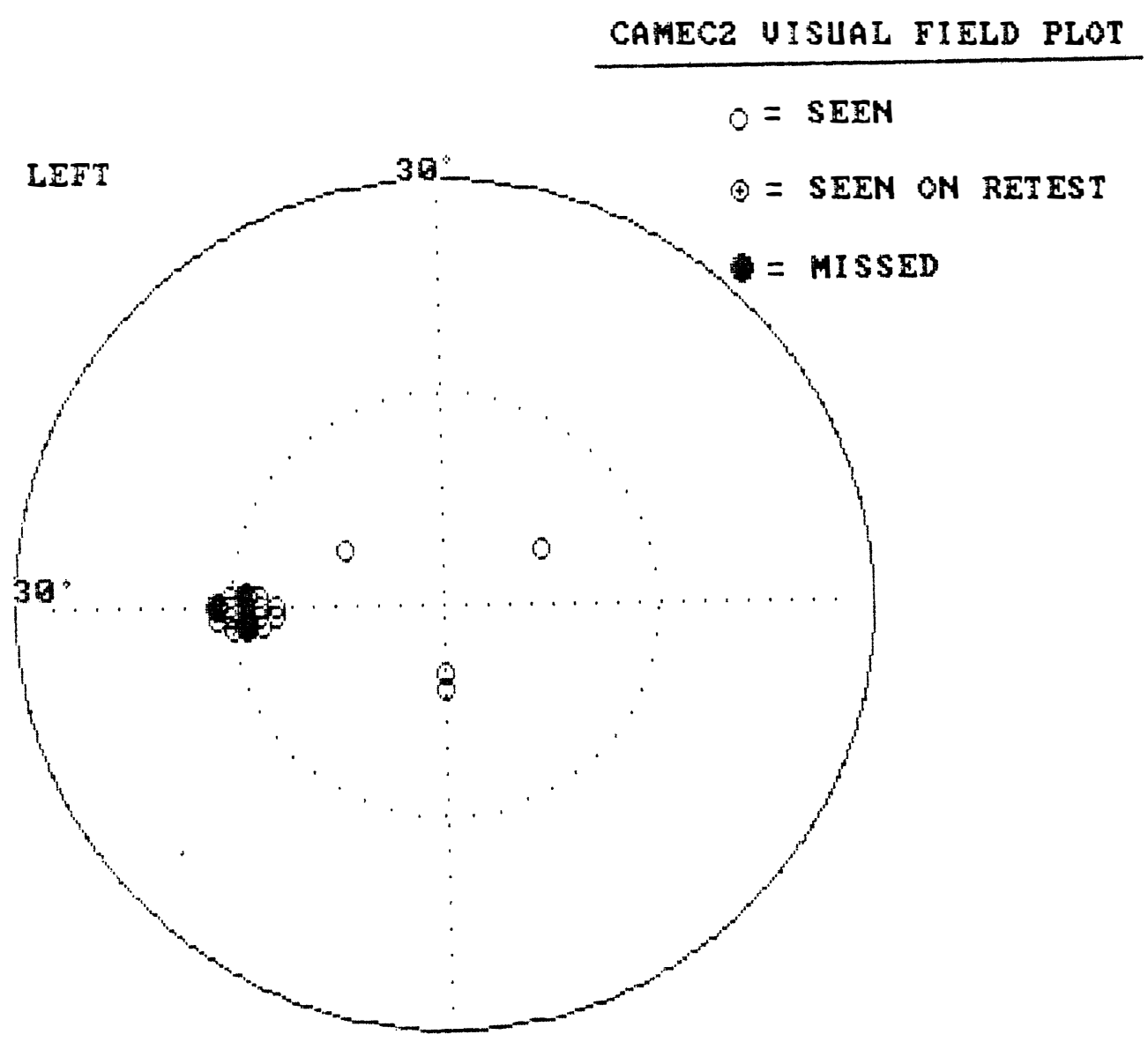

Fig. 2. The blind spot program test grids of Dicon (top) and CAMEC (bottom). 
Table I. The test parameters used in the Dicon and CAMEC programs

\begin{tabular}{lll}
\hline & Dicon & CAMEC \\
\hline Background type & Bowl & Video display \\
& White & Whit \\
Background luminance & 10 apostilbs & 32 apostilbs \\
Stimulus type & Static, bright (light- & Static, black \\
& emitting diode) & \\
Stimulus luminance & 500 apostilbs & 8 apostilbs \\
Stimulus duration & $0.3 \mathrm{~s}$ & $0.3 \mathrm{~s}$ \\
Stimulus area & $2 \mathrm{~mm}^{2}$ & $5 \mathrm{~mm}^{2}$ \\
\hline
\end{tabular}

The coordinates of the points to be tested, the background luminance, and the size, intensity and duration of the stimuli are all set before the examination by means of menu-driven software. Any test strategy can be saved for subsequent use or modification at a later date. The results are automatically displayed on screen, printed on paper and saved on disc.

A total of 32 normal eyes (19 right, 13 left) of 32 consecutive patients (15 boys, 17 girls) aged 4-10 years (mean $5.8 \pm 1.5$ years) who were attending the Orthoptic Clinic were included in this study (Fig. 1). All eyes had a visual acuity of 6/9 or better. Each eye was examined by both the Dicon Auto-Perimeter fitted with a video fixation monitor (Cooper-Vision Inc.) and CAMEC. Each patient was tested with both the 'Blind Spot Program' of Dicon, which presents 13 stimuli in a $5^{\circ} \times 7^{\circ}$ area at the blind spot location and an additional eight stimuli in the surrounding periphery, and a similar CAMEC program which presents 14 stimuli in the blind spot (Fig. 2). The parameters of both techniques used in the study are given in Table I. The order of the two tests was selected randomly for all cases. Sixteen eyes were tested with Dicon first and 16 eyes were tested first with CAMEC. Both tests were carried out in the presence of at least one parent. All subjects were initially given the demonstration program of each device during which they were also reminded repeatedly to look at the fixation target only. Once the child was familiar with the requirements of the test procedure, the examination was performed without any further intervention.

The percentage ratio of the number of missed stimuli to the total number of stimulus presentations in the blind spot area was the test score for each technique. The scores from the two visual field test methods were compared using the Wilcoxon signed-rank test.

Table II. The details of children who could not complete either or both tests

\begin{tabular}{lccccc}
\hline Patient no. & Age $(\mathrm{yr})$ & Sex & Eye & Dicon & CAMEC \\
\hline 1 & 4 & $\mathrm{~F}$ & $\mathrm{~L}$ & $(-)$ & $(-)$ \\
2 & 5 & $\mathrm{~F}$ & $\mathrm{~L}$ & $(-)$ & $(-)$ \\
3 & 4 & $\mathrm{~F}$ & $\mathrm{R}$ & $(+)$ & $(-)$ \\
4 & 4.5 & $\mathrm{M}$ & $\mathrm{L}$ & $(-)$ & $(+)$ \\
5 & 5.5 & $\mathrm{~F}$ & $\mathrm{R}$ & $(-)$ & $(-)$ \\
6 & 4.5 & $\mathrm{M}$ & $\mathrm{R}$ & $(-)$ & $(-)$ \\
7 & 4 & $\mathrm{M}$ & $\mathrm{R}$ & $(-)$ & $(-)$ \\
8 & 4 & $\mathrm{~F}$ & $\mathrm{~L}$ & $(-)$ & $(-)$ \\
\hline
\end{tabular}

$(+)$, test completed; (-), test abandoned; M, male; F, female; R, right; $\mathrm{L}$, left.

\section{RESULTS}

Twenty-four of the 32 children performed and completed both tests successfully. The details of the patients who could not cooperate sufficiently on either test and the number of abandoned tests are given in Table II.

Among the 24 patients who successfully completed both tests, the blind spot was detected in 18 eyes $(75 \%)$ by the Dicon Auto-Perimeter and in 24 eyes (100\%) by CAMEC. The full scores from all patients are shown in Fig. 3.

The blind spot detection scores were significantly higher with CAMEC (mean $61.0 \%$, SD 22.5\%, range 14$100 \%$ ) than with the Dicon Auto-Perimeter (mean 26.6\%, SD $24.1 \%$, range $0-77 \%$ ) (Wilcoxon test, $p<0.001$ ).

\section{DISCUSSION}

The use of computer graphics and video display units has been described previously in the analysis of visual fields. ${ }^{7,8}$ The unique moving fixation target of CAMEC controls the patient's direction of gaze, thus enabling the child to perform the test successfully (Figs. 4-6). The results of this study suggest that CAMEC can be used by most children above the age of 5 years when motor development is sufficient to use a joystick effectively, and that visual field defects can be detected in patients who can not be assessed properly using conventional methods (Fig. 7). Additionally, the higher scores with CAMEC than Dicon confirm that fixation is maintained better with a moving fixation target than a stationary target. This further suggests that in the paediatric age group a moving eye fixation method should allow more accuracy in quantification of visual field abnormalities than conventional 'oculostatic' methods.

In summary, CAMEC was found to be a useful way of examining the visual field in children aged 5 years or more.

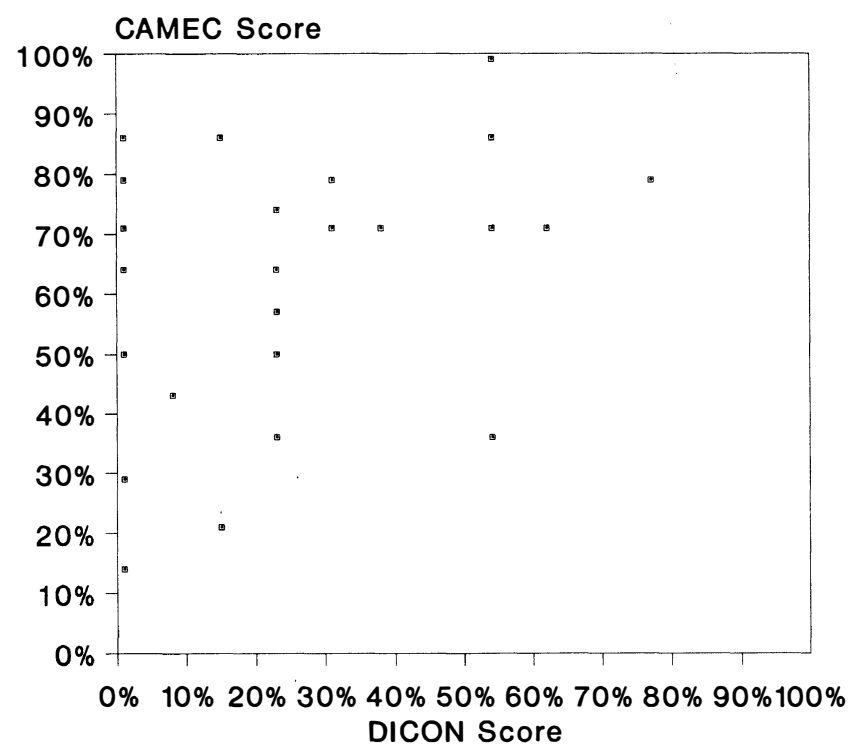

Fig. 3. The CAMEC scores against the Dicon scores in the 24 patients who completed both tests. Moving fixation technique of CAMEC provided better fixation maintenance resulting in higher detection rate and better quantification of the visual field defect. 
FIYATION LOSSES O/1

FALSE FOS ERRORS O

FAII.EE NEI: ERPOFS D.

L.EFT

F: I DHT

FALSE POS EFFORS O

FALSE NEC EFPOFS O\%

TEST TIME D0:05:00

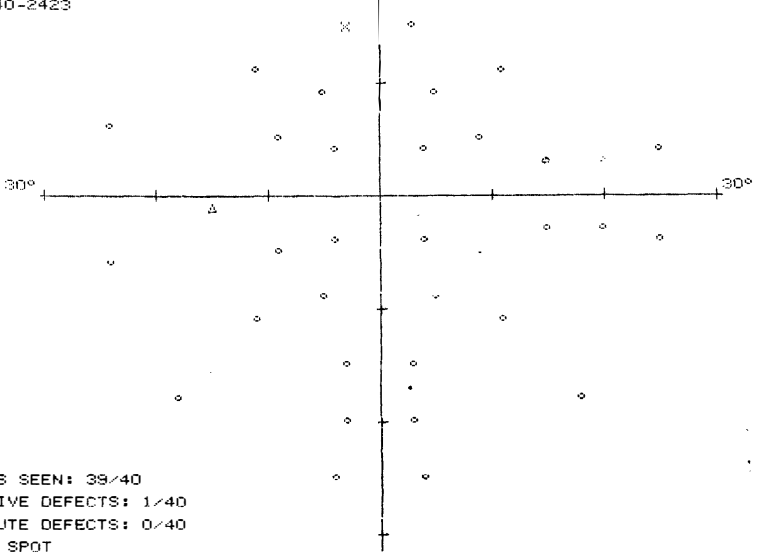

TEST TIME OII: חS:0F

$Y=$ FEELATIVE DEFECTS: $1 / 40$

- = HESOLUTE DEFECTS: 0.40

$A=$ ELIND SPOT

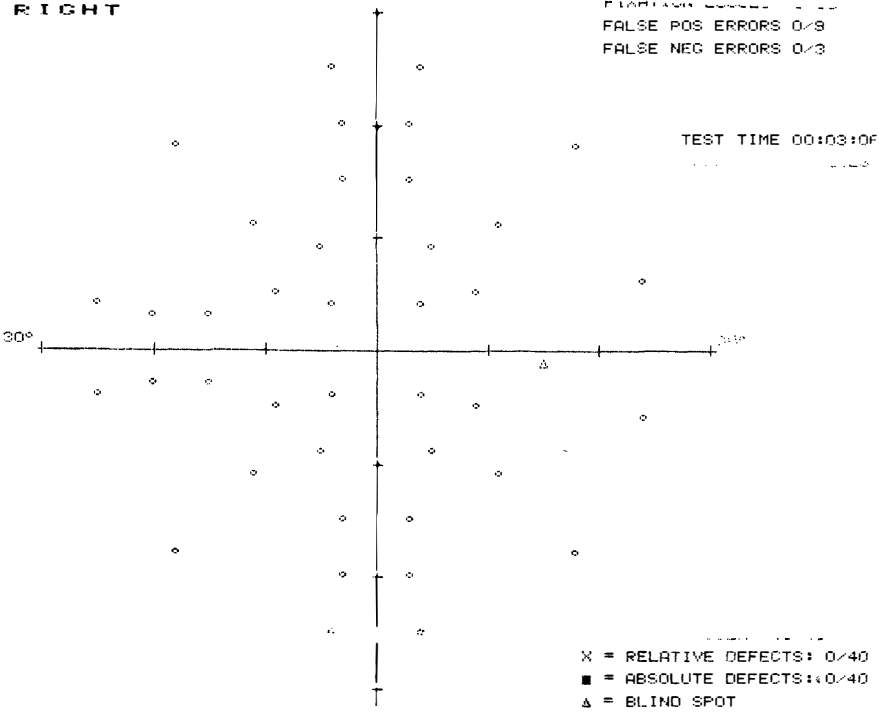

Fig. 4a.

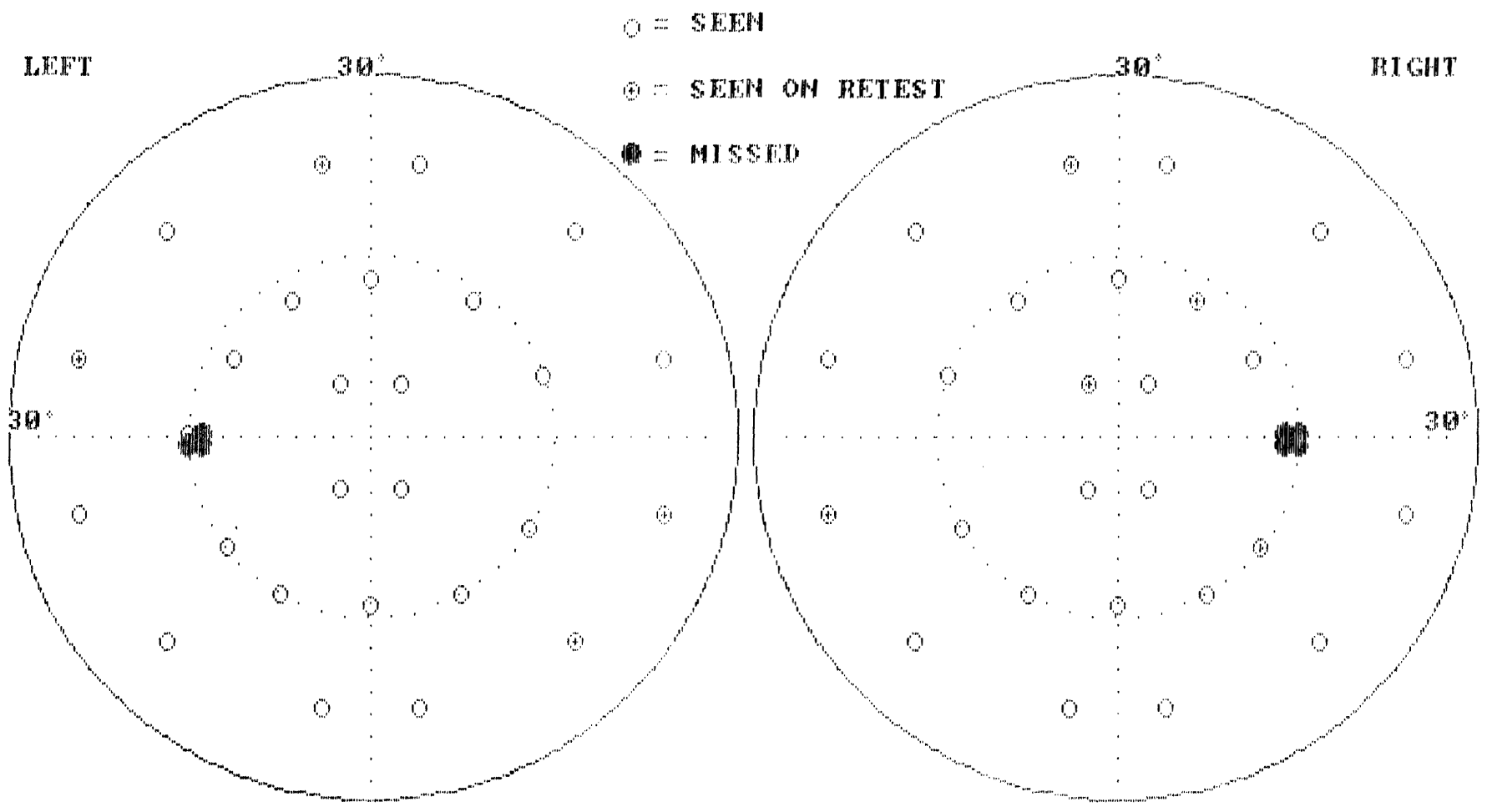

No. Seren: $z^{2} L_{0}$

Faisen Nerat ines: 4

Fal se pos it ives

stimulus indelons of arod: 12

stinulus buration $(5)$ : 0.30

Agre:

Mon. Serten: at

Mo Micsed: a

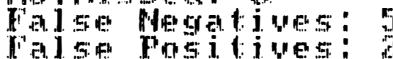

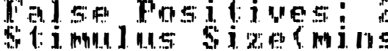

ins of and : 1

Name:

0a t: $: 27-93-199$

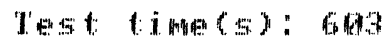

Fig. 4b.

Fig. 4. The suprathreshold screening programs of (a) the Humphrey visual field analyser (VFA) and (b) CAMEC showing full and normal visual field test results from an 8-year-old child with good co-operation. 
FTRATION 1.98SES $\$ 10 \times$ FO! GE FOS EFFOFS D

FFI SE NEC EPEORS I

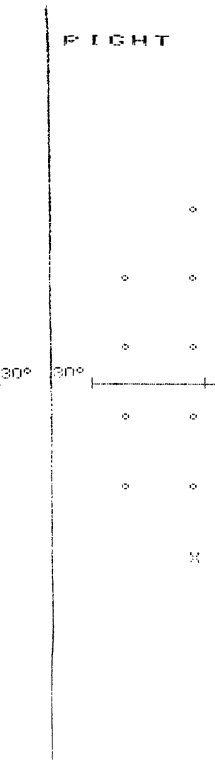

FIVATIOH L IOSES FFI SE RTE EFFIFS 1 FAl GE MET, EFFTFE:
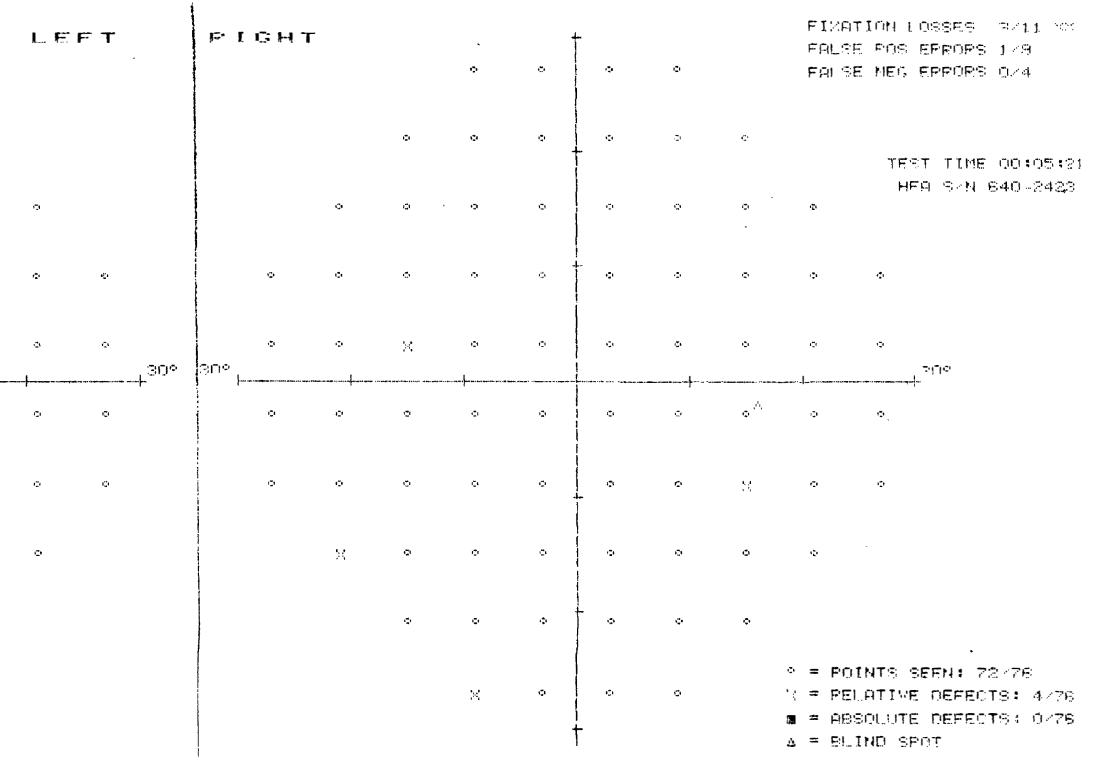

Fig. 5a.

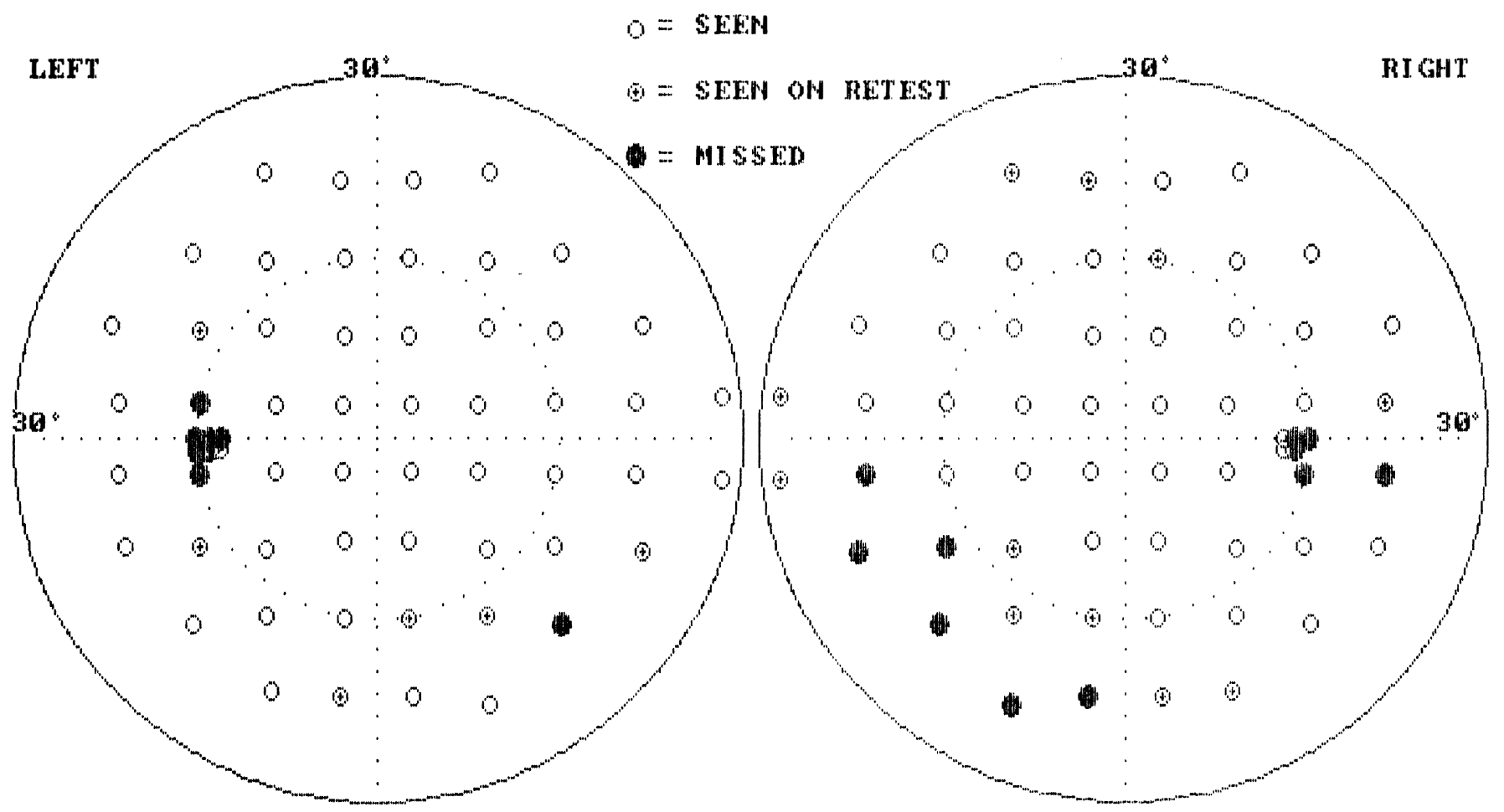

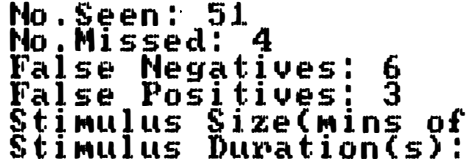

stimulus Duration(s)?

Name: $\operatorname{arc}): 12$

Age:
No. Seen: 46

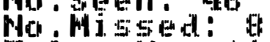

Fise peration: 11

stimulus 5 idx (mins of axc): 12

Stimulus buration(s): 0. Ad

Test time(s): 843

Fig. 5b.

Fig. 5. Both CAMEC and the Humphrey VFA produced an infero-nasal defect to the identical grids of suprathreshold (a) bright and (b) dark stimuli in the right eye of this 7.5 year-old boy with intraorbital compressive optic neuropathy. The defect to the light stimulus of the Humphrey VFA appears less significant than that to the dark stimulus of CAMEC, probably because of both the alarmingly high frequency of fixation losses (3/11) and the more extensive nature of the field defects to dark stimulus. ${ }^{9-11}$ The left visual field was normal. 


\section{EEHTFAL FE FUIMT EEFEEMIMETEST}

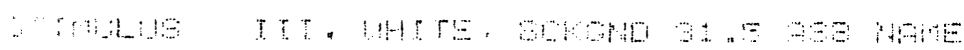

Q. INO SFOT EHECH BITE III ID

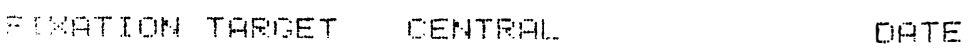

- FATEG THFEE ZOHE

EH 34 De

FIFIL DITHETEF:

FU: $18 E$

EIF:THEIATE

TIPIE $\quad 0: 10: 19$

Fiv:

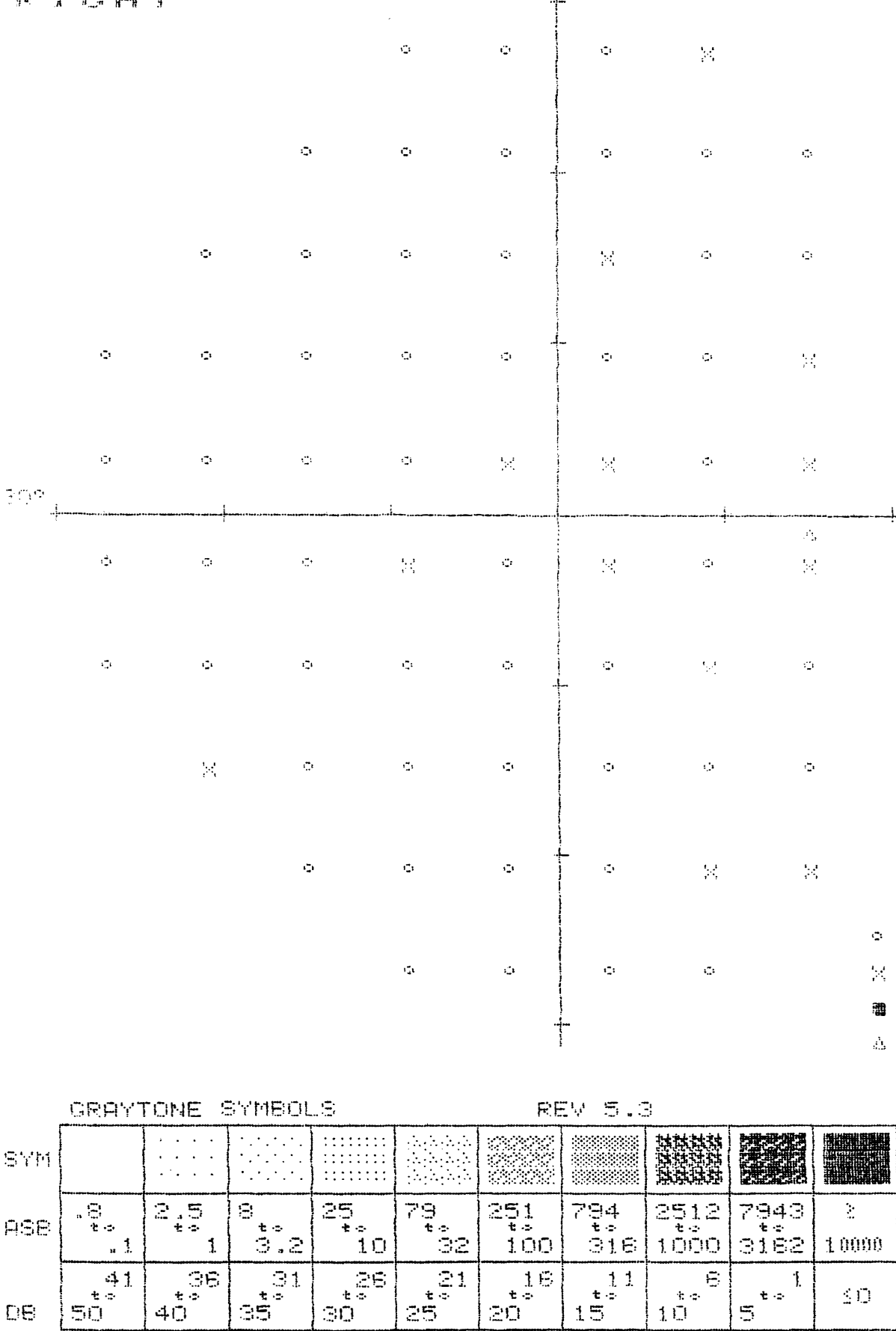

TEET TTHE TIM

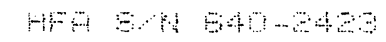

FINTTH LOEEG 9 14

FALEE PRE EPRTES 19

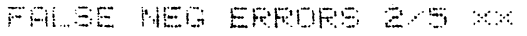

$\therefore$ = PUIHTS SEEH EOTO

$Y$ = FEMTTEE DEFECTE: 19 OY

= AESTHUTE DEFECTE: 1 TE

$\therefore=$ BLTHL EFTT

Fig. 6a. See next page for legend. 

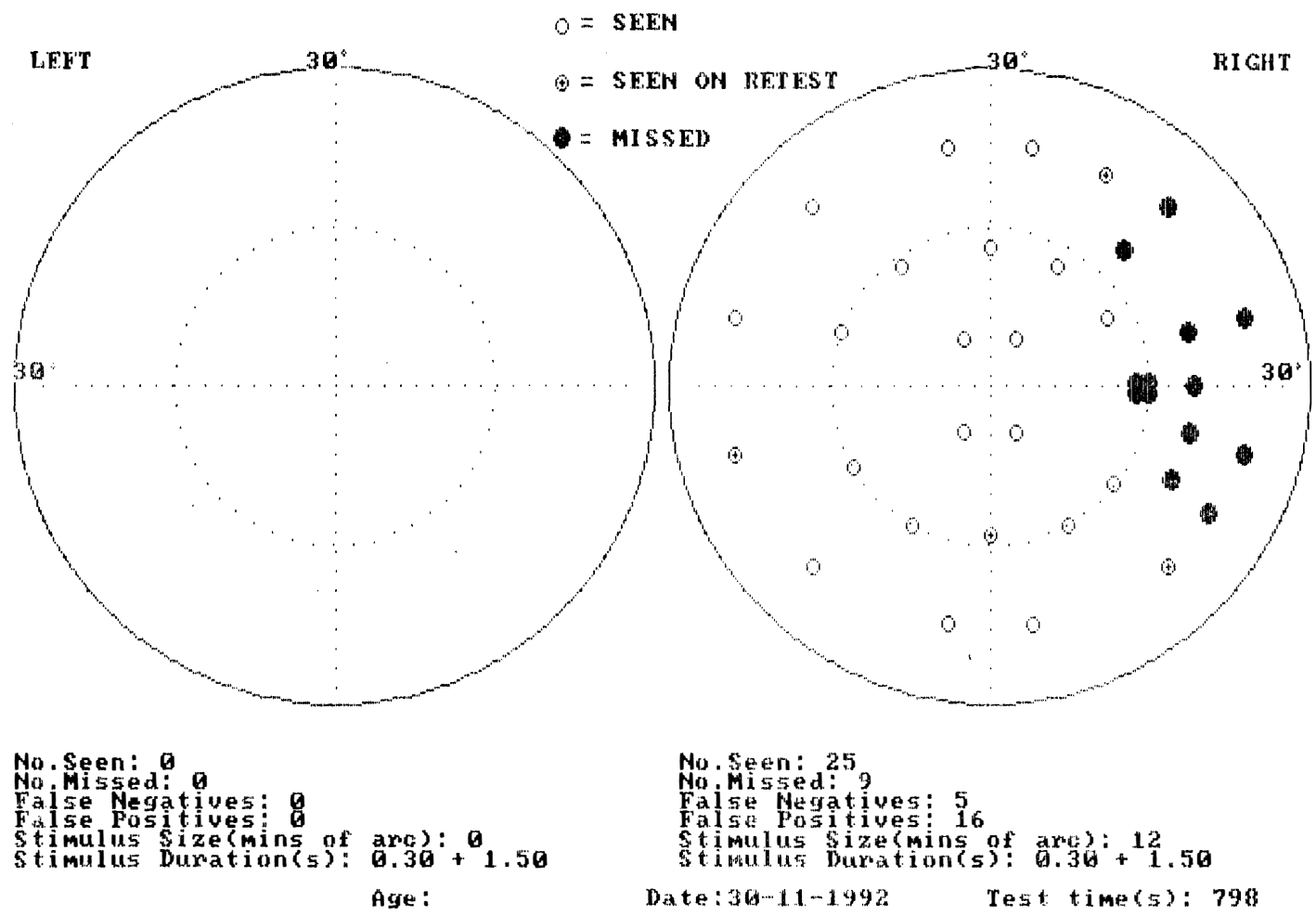

Fig. 6b.

Fig. 6. (a) Conventional Humphrey VFA and (b) CAMEC test results of a 9-year-old boy. The patient had a residual temporal field loss in the right eye and no perception of light in the left due to a left optic nerve glioma. The tumour, which extended to the chiasmal hypothalamic region, had been removed in the past. The abnormal points on the conventional field result scatter in the temporal hemifield because of.too many fixation losses (9/14) and false negative answers (2/5).
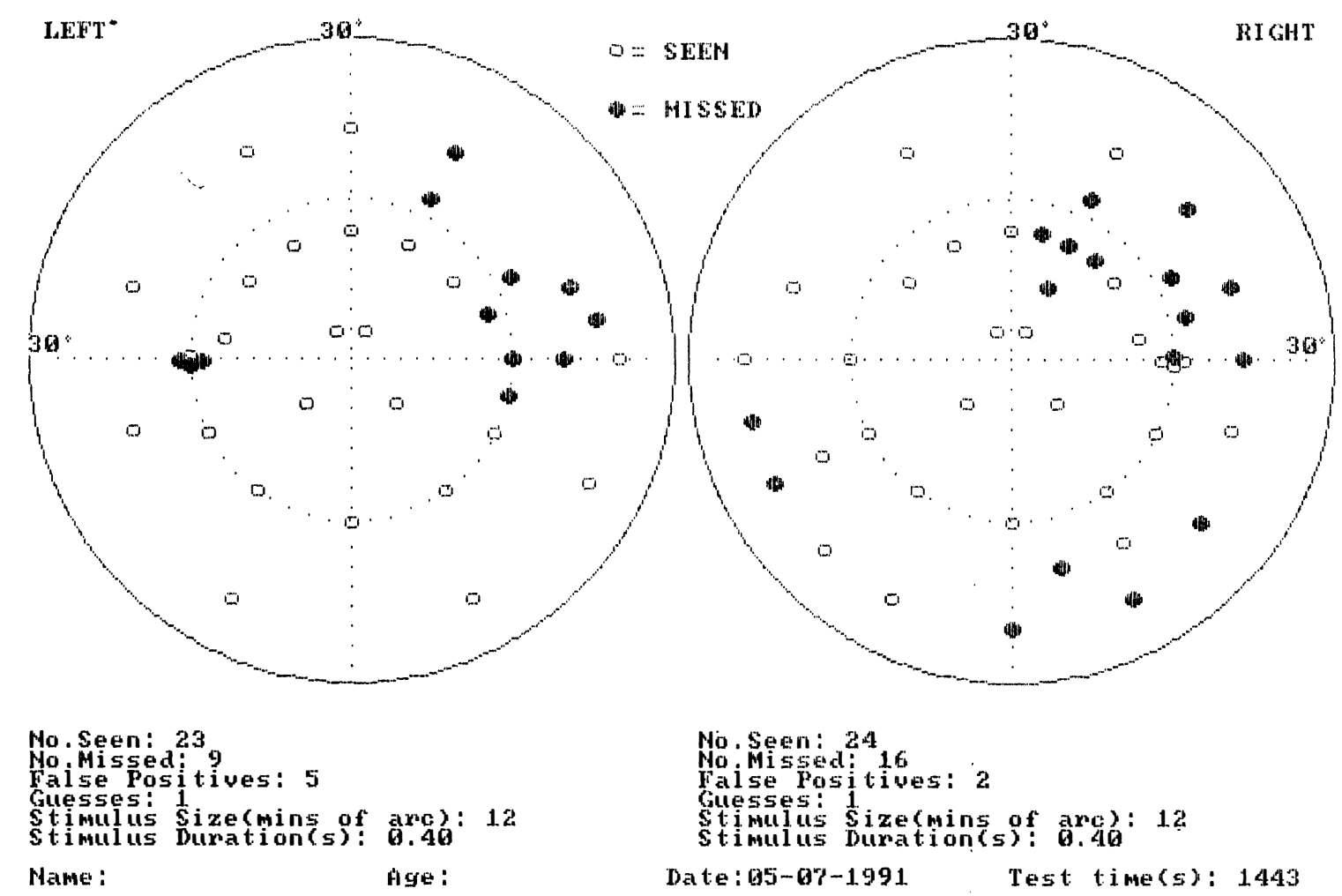

Fig. 7. CAMEC revealed a supero-temporal homonymous quadrantal visual field defect in both eyes of this 5.5-year-old girl who could not be examined with conventional perimetric methods. The presence of intracranial (left temporal lobe) pathology was subsequently confirmed with computed tomography. 
We are grateful to orthoptists Mrs. R. Andrews, Mrs. H. Burnett and Mrs. V. Carmichael for their permission to examine their patients. This study was funded by the Royal National Institute for the Blind, International Glaucoma Association and W. H. Ross Foundation for the Prevention of Blindness.

Key words: Automated perimetry, Blind spot, Eye movement, Paediatric ophthalmology, Perimetry, Psychophysics, Visual field.

\section{REFERENCES}

1. Cummings M, Mayer DL, Hansen RM, Fulton AB. An LED perimetric method to study peripheral vision of infants and children. Infant Behav Dev (Special ICIS issue) 1986;9:91-103.

2. Mayer DL, Fulton AB, Cummings MF. Visual fields of infants assessed with a new perimetric technique. Invest Ophthalmol Vis Sci 1988;29:452-9.

3. Fausset TM. A rapid technique for kinetic visual field determination in young children and adults with central retinal lesions. Doc Ophthalmol Proc Ser 1986;49:495-501.

4. Barnard NAS. Kinetic outline perimetry as a technique for examining the visual fields of young children (letter). Ophthalmic Physiol Opt 1988;8:463-4.
5. Johnson SC, Damato BE, Evans AL, Allan D. Computerised visual field test for children using multiple moving fixation targets. Med Biol Engin Comput 1989;27:612-6.

6. Damato BE, Mutlukan E, McGarvie J, Evans A. Computer assisted moving eye campimetry. In: Mills R, editor. Perimetry update 92/93. Amsterdam: Kugler and Ghedini, 1993 (in press).

7. Accornero N. Computerised video screen perimetry. Arch Ophthalmol 1984;102:40-1.

8. Goni FJ, Guarro M, Sanchez-Dalmau B. Computer campimetry: general fundamentals for its clinical application. Ann d'Ophtalmol 1991;1(4):13-23.

9. Mutlukan E, Damato BE. Visibility threshold for dark perimetric stimulus. In: Mills R, editor. Perimetry update 92/93. Amsterdam: Kugler-Ghedini, 1993 (in press).

10. Mutlukan E. Computerised off-pathway testing. Presented at symposium on ophthalmological image processing. The Rank Prize Funds, England, 1992.

11. Mutlukan E, Damato BE, McFadzean R, McGarvie J, Evans A. Computer assisted moving eye campimetry in neuroophthalmology. Presented at the IXth international neuroophthalmology symposium, Williamsburgh, Virginia, USA, 1992. 